\title{
Evaluation of forest fire on Madeira Island using Sentinel-2A MSI imagery
}

Gabriel Navarro ${ }^{1 *}$, Isabel Caballero ${ }^{1}$, Gustavo Silva ${ }^{2}$, Pedro-Cecilio Parra ${ }^{3}$, Águeda Vázquez ${ }^{4}$, Rui Caldeira ${ }^{2}$.

1. Departamento de Ecología y Gestión Costera, Instituto de Ciencias Marinas de Andalucía, ICMAN-CSIC, 11510, Puerto Real, Spain.

2. Observatório Oceânico da Madeira, OOM-ARDITI, 9020-105, Funchal, Portugal.

3. Proyectos de Ingeniería Medioambiental (PIMA), 02640, Almansa, Spain.

4. Escuela Superior de Ingeniería, Universidad de Cádiz, 11510, Puerto Real, (Spain).

* Corresponding author:

Gabriel Navarro

Department of Ecology and Coastal Management

Institute of Marine Sciences of Andalusia (ICMAN-CSIC)

Avda. Republica Saharaui, 2.

11510- Puerto Real

Cádiz

Spain

email: gabriel.navarro@icman.csic.es

Tel: +34956832612 ext235

Fax: +34 956834701 


\begin{abstract}
A forest fire started on August $8^{\text {th }}, 2016$ in several places on Madeira Island causing damage and casualties. As of August $10^{\text {th }}$ the local media had reported the death of three people, over 200 people injured, over 950 habitants evacuated, and 50 houses damaged. This study presents the preliminary results of the assessment of several spectral indices to evaluate the burn severity of Madeira fires during August 2016. These spectral indices were calculated using the new European satellite Sentinel-2A launched in June 2015. The study confirmed the advantages of several spectral indices such as Normalized Difference Vegetation Index (NDVI), Green Normalized Difference Vegetation Index (GNDVI), Normalized Burn Ratio (NBR) and Normalized Difference Vegetation Index (NDVIreXn) using red-edge spectral bands to assess the post-fire conditions. Results showed high correlation between NDVI, GNDVI, NBR and NDVIre1n spectral indices and the analysis performed by Copernicus Emergency Management Service (EMSR175), considered as the reference truth. Regarding the rededge spectral indices, the NDVIre1n (using band B5, 705nm) presented better results compared with B6 $(740 \mathrm{~nm})$ and B7 $(783 \mathrm{~nm})$ bands. These preliminary results allow us to assume that Sentinel-2 will be a valuable tool for post-fire monitoring. In the future, the two twin Sentinel-2 satellites will offer global coverage of the Madeira Archipelago every five days, therefore allowing the simultaneous study of the evolution of the burnt area and reforestation information with high spatial (up to $10 \mathrm{~m}$ ) and temporal resolution (5 days).
\end{abstract}

Keywords: Madeira Fires, Sentinel-2, Spectral indices, Burn severity 


\section{Introduction}

Madeira is a Portuguese archipelago located in the North Atlantic Ocean, southwest of Portugal (Fig. 1). Madeira Island is the largest island of the archipelago with an area of $741 \mathrm{~km}^{2}$, a length of $57 \mathrm{~km}$ (approximately $22 \mathrm{~km}$ at its widest point), and a coastline of $150 \mathrm{~km}$. It has a mountain ridge that extends along the centre of the island, reaching 1,862 $\mathrm{m}$ at its highest point. Over the last few years, several fires were started on Madeira Island. In August 2010, the largest of the fires burned through 95 percent of the Funchal Ecological Park, a 1,000-hectare preserve allocated to restore native vegetation to the island. The park's mountainous terrain extends from $520 \mathrm{~m}$ to $1,818 \mathrm{~m}$ in elevation over a short distance; this steep region poses a challenge to fire fighters. Recently, a forest fire started on August $8^{\text {th }}, 2016$ and affected both forest and residential areas in Câmara de Lobos, Ribeira Brava, Ponta do Sol, Calheta, and especially the regional capital of Funchal (Fig. 1). Several homes have been destroyed and thousands of people were evacuated. As of August $10^{\text {th }}$, the local media, reported the death of three people, over 200 people injured, over 950 habitants evacuated, and 50 houses damaged. The Copernicus Emergency Management Service determined the perimeter of the fires, as well as the distribution of the severity levels inside it, facilitating the decision making process (Fig. 2).

Since the mid-1980s, remote sensing (RS) tools have proven useful to accurately estimate fire-affected areas and burn severity, to aid in forest fire prevention, assessment, and monitoring on global, regional, and local scales (Chu and Guo, 2014; Chuvieco, 2009; Lentile et al., 2006). These techniques have been employed to address three different temporal fire-effect phases: pre-fire conditions, active fire characteristics and post-fire ecosystem responses (Chu and Guo, 2014 and references therein). Space and airborne sensors have been used to assess environmental conditions before and 
during fires and to detect changes in post-fire spectral responses, which examine the vegetation response (Lentile et al., 2006 and references therein). These datasets are generally available for multiple spatial and temporal resolutions.

These sensors, which have also been used to evaluate the burnt area, include the Advanced Long Track Scanning Radiometer (Eva and Lambin, 1998), Advanced Very High Resolution Radiometer (AVHRR) (Flannigan and Vonder Haar, 1986), Moderate Resolution Imaging Spectrometer (MODIS) (Roy et al., 2005), Systeme Pour I'Observation de la Terre Vegetation (SPOT-VEGETATION) (Stroppiana et al., 2002), and Landsat (Holden et al., 2005; Salvador et al., 2000). Table 1 in Lentile et al. (2006) and Table 2 in Chu and Guo (2014) summarize the characteristics of the RS system relevant to fire detection and monitoring, including visible (VIS), near-infrared (NIR), mid-infrared (MIR) and thermal infrared (TIR). These array RS sensors have been widely used for both detecting active fires and mapping burned scars due to their high quality in terms of temporal and spectral resolution.

Recently, the European Space Agency (ESA) launched the Sentinel-2A satellite (June $23^{\text {rd }}, 2015$ ), the first of the two-satellite Sentinel-2 mission. The Europe's Copernicus environmental monitoring programme, Sentinel-2, gives continuity to the multispectral high-resolution optical observations over global terrestrial surfaces provided by the ESA through the SPOT series of satellites (Fletcher, 2012). Sentinel-2A carries an innovative wide-swath, high-resolution, MultiSpectral Instrument (MSI). The design of the MSI has been driven by the requirement for large swath high geometrical and spectral performance of the measurements. The MSI measures the Earth's reflected radiance over 13 spectral bands (Table 1). These spectral bands span from VIS and NIR, to short wave infrared (SWIR), at different spatial resolutions (Malenovsky et al., 2012), offering a great potential for fulfilling the satellite data requirements for fine 
scale mapping of vegetation. The MSI sensor records data in the vegetation red-edge spectral domain which is one of the best RS based descriptors of chlorophyll content (Curran et al., 1990). In fact, recently Fernández-Manso et al. (2016) have evaluated the potential of these red-edge spectral bands to discriminate burn severity levels in a fire located in Sierra de Gata (central-western Spain).

Because of this, we have obtained two Sentinel-2A images (pre-fire and postfire, Table 2) to evaluate the burnt areas in Madeira Island corresponding to fires produced during August 2016. The Sentinel-2A's high spatial resolution, allows us to assess the degree of fire heterogeneity, exhibiting the great potential for studying finescale heterogeneity in fire-effects across large areas. Those studies could help us understand both the causes and consequences of spatial variability of post-fire effects. Therefore, the main aim of our study was to test the suitability of Sentinel-2 MSI data for mapping different spectral indices related to the burn severity of the Madeira Island fire. These indices are cost-effective and spatially comprehensive views of both areas that have been affected by fire in different fire grading.

\section{Material and Methods}

The study area is focuses on two regions of Madeira Island (central-western part and Funchal area, Fig. 2) where a wildfire started on August $8^{\text {th }}, 2016$ burning 79.50 $\mathrm{km}^{2}$ according to the Copernicus European programme. In Calheta (central-western part, Fig. 2b) the affected vegetation was mainly large area covered by trees, which mainly included maritime pines, acacias, eucalyptus, softwoods/broadleaved, bushes, and herbaceous plants, while also destroying a small percentage of Madeira's natural laurel forest. Although in Funchal, the fire affected mostly buildings (urbanised areas), bushes, herbaceous plants and forest areas like acacia, eucalyptus and maritime pine 
(northern section of Fig. 2c) (IFRAM2, 2015). The fire grading of the different areas (Fig. 2b and 2c) were obtained from the Copernicus Emergency Management Service website (EMSR175) and was considered as reference truth. The map (Fig. 2b and 2c) displays four levels of burn severity: completely destroyed area (CD), highly damaged area (HD), moderately damaged area (MD) and possibly damaged area (PD). PD level only appeared in Funchal fire (Fig. 2). These areas were based on SPOT6 data (acquired on August 12 $2^{\text {th }}, 2016$ 11:23 UTC and distributed by Airbus DS).

The two Sentinel-2A Level-1C (L1C) MSI images (Table 2) used in this study were downloaded from the Sentinel's Scientific Data Hub (https://scihub.copernicus.eu/). These images correspond to Level-1C products processed by the Payload Data Ground Segment (PDGS), which means data are radiometrically and geometrically corrected Top-Of-Atmosphere (TOA) products. The corrections include orthorectification and spatial registration on a global reference system (ortho-images in UTM/WGS84 projection) with sub-pixel accuracy. L1C images are delivered in tiles of $100 \mathrm{~km}^{2}$. These images were processed to Level-2 data by using Sentinel-2 Toolbox (SentiNel Application Platform, SNAP v2.0.2.), which consists of a rich set of visualization, analysis and processing tools for the exploitation of MSI data from the upcoming Sentinel-2 mission. The atmospheric correction procedure was executed with the installation of Sen2Cor plugin (Sentinel to Correction, v2.2.1) (TVD, 2015), which is a prototype processor for Sentinel-2 Level-2A (L2A) product formatting and processing. This procedure in the common platform for the Sentinel toolboxes will be the atmospheric correction procedure accessible to the entire scientific community as open source software ideal for Earth Observation processing and analysis (Toming et al., 2016). It has been recently applied to precisely detect a variety of landscape features (Radoux et al., 2016). However, other attempts have been 
recently adopted to scale Sentinel-2A MSI bands to surface reflectance, as in the study performed by Fernández-Manso et al. (2006) using Dark Object Subtraction (DOS) (Chavez, 1988).

Sen2cor performs a pre-processing of L1C Top-of-Atmosphere (TOA) image data, and applies a scene classification with an atmospheric, terrain and cirrus correction and a subsequent conversion into an ortho-image L2A Bottom-Of-Atmosphere (BOA) reflectance product. Level-2A outputs are Bottom-Of-Atmosphere (BOA), optionally terrain and cirrus corrected reflectance images, Aerosol Optical Thickness (AOT), Water Vapour (WV), Scene Classification maps and Quality Indicators, including cloud and snow probabilities. L2A products are re-sampled as L1C products with a constant Ground Sampling Distance (GSD) of $10 \mathrm{~m}, 20 \mathrm{~m}$ and $60 \mathrm{~m}$ according to the native resolution of the different spectral bands (Table 1). Later, with some of the subscenes (T28SBB: western part and T28SCB: eastern part) located along Madeira Island a mosaic was carried out using QGIS (v2.14.0) for each spectral band. The post-fire image (Table 2) showed partial cloud-coverage over Funchal area (Fig. 2). Therefore, by using the Scene Classification algorithm (L2A_SceneClass), we performed a cloud mask for this scene in order to eliminate cloud pixels for further statistical analysis. This algorithm allows us to detect clouds, snow, and cloud shadows and to generate a classification map, which contains of 4 different classes for clouds (including cirrus).

Several spectral indices related with fire and burnt areas were calculated (Table 3) for Madeira Island. These indices showed the capacity to discriminate burnt areas, especially the spectral indices combining the red-edge bands (Fernandez-Manso et al., 2016). We have used narrowband NIR (B8a) instead of broadband NIR (B8) since the differences found by Fernandez-Manso et al. (2016) were not significant. In addition, the spatial resolution of the red-edge bands (B5, B6 and B7: Table 1) used in this study 
was $20 \mathrm{~m}$. Therefore, the mosaic for each band was created using a spatial resolution of $20 \mathrm{~m}$.

\section{Results and Discussion}

Fire severity can be defined as the degree of change in soil and vegetation caused by fire (Escuin et al., 2008). The determination of the fire perimeter, and distribution of severity levels inside it, facilitates the decision making process aimed at restoring the affected areas which includes analysing fire-effects on the post-fire vegetation restoration. One of the most used spectral indices to assess burn severity by means of remote sensing is the Normalized Difference Vegetation Index (NDVI), which includes the uni-temporal (pre-fire or post-fire) and bi-temporal (pre-/post-fire difference, dNDVI). The NDVI is shown in Fig. 3 from the uni-temporal point of view (pre-fire and post-fire) and bi-temporal point of view (dNDVI, Table 3), where the notable decrease in the NDVI index values recorded in the fire region indicate the surface affected by the fire (Fig. 3c). The high values of the dNDVI (around 0.70) were found in the northern part of the Calheta fire (Fig. 3c), corresponding to areas catalogued as completely destroyed (Table 4). Fig. 3c shows the difference between these values for each area related with fire grading. The MSI image corresponding to the post-fire event (August $17^{\text {th }}, 2016$ ) presents clouds in the Funchal area (Fig. 2a), therefore the results of these analyses are focused only in Calheta fire area (Fig. 2b).

Comparable results were found using a similar spectral index like Green Normalized Difference Vegetation Index (GNDVI) (Fig. 4). We used this spectral index because it has shown better results in the study performed by Fernández-Manso et al. (2016) using Sentinel-2 MSI images. Reduction of the saturation effect in denser vegetation can be observed when replacing the red band by the green band (GNDVI 
instead of NDVI). GNDVI was argued to be at least five times more sensitive to chlorophyll-a concentration than the NDVI and specifically useful for differentiating stressed and senescent vegetation (Gitelson et al., 1996). The reduction of the NDVI and GNDVI is due to increase in the visible region of the electromagnetic spectrum and a decrease in the NIR region due to the fire consuming the vegetation, destroying the chlorophyll, leaving the soil bare, charring the roots and altering the soil's moisture. Díaz-Delgado et al. (2003) found a positive correlation between the drop in NDVI index values and fire severity levels inside the fire's perimeter in Barcelona province (Northeast Spain). The decrease of NDVI in some areas might be due to background noise, such as snow cover and vegetation senescence (Fraser et al., 2000). However, in Madeira Island these conditions did not occur. These indices have been widely used to assess burn severity through RS in several Mediterranean areas (Chuvieco et al., 2002; Escuin et al., 2008; Fernandez-Manso et al., 2016), boreal regions (Barrett et al., 2010; Epting et al., 2005) and African Savannah (Roy et al., 2005; Smith et al., 2005).

Along with NDVI and GNDVI (pre-fire, post-fire and pre-post difference), the Normalized Burn Ratio (NBR) and Normalized Burn Ratio difference (dNBR) have been also analysed (Fig. 5). These indices are widely being used to assess landscapescale post-fire effects. NBR allowed significant discrimination of the third burn severity level in Madeira Island fires, though levels CD, HD and MD (Fig. 6, Table 4). In areas of vegetation it shows positive values, while its negative values correspond to bare soil (Completely destroyed, CD).

In burnt areas, NDVI, GNDVI and NBR values decrease at the same time as the fire severity rises (Fig. 6, Table 4). Several studies have demonstrated the relationship between the dNBR index and fire severity in USA (Cocke et al., 2005; Key and Benson, 1999; Kokaly et al., 2007; van Wagtendonk et al., 2004) and in southern African 
savannas (Roy et al., 2005; Smith et al., 2005). This index was used in the Mediterranean areas for the discrimination of burnt areas and even for the monitoring of post-fire vegetation (López and Caselles, 1991).

Finally, other indices using the red-edge bands (B5, B6 and B7, Table 3) instead of the red band (B4) have been computed and displayed in Fig. 7 in order to compare their evaluation. Clearly, the NDVIre1n spectral index shows the best result to define the burnt area of the Calheta fire. The box-plot for each spectral index using the rededge bands show differences in NDVIre1n post-fire values for each area (fire grading). On the contrary, the box-plot values (Fig. 8 and Table 4) for each area (CD, HD and MD) for spectral indices using B6 (NDVIre2n) and B7 (NDVIre3n) show similar values, hindering the differentiation of the different areas. Therefore, NDVIre1n show better discretisation of the burn severity levels (Fig. 8) than NDVIre2n and NDVIr3n indices. This corroborates earlier research findings (Fernández-Manso et al., 2016), where NDVIre1n was the best spectral index to discriminate burn severity using Sentinel-2A MSI images. Changes in spectral signatures that occur following a fire can be alternates for identifying patterns of burnt areas. When vegetation is burned, there is a drastic reduction in visible-to-near-infrared reflectance accompanied with an increase in the short and middle infrared surface reflectance of most satellite sensors (Lentile et al., 2006). Burnt patches are relatively easy to visually discriminate (Bastarrika et al., 2011) for this reason. Results showed that indices with red-edge spectral bands still yielded better results than indices lacking a red band.

Therefore, the identification and classification of the forest successional stages over large areas are challenging to conduct based on field surveys alone. Combining field plots with remotely sensed data, however, provides an alternative approach for monitoring successional stages of forest across large spatial areas. Lentile et al. (2006) 
summarized field-based measurements of post-fire effects to include an assessment of changes in soil colour, soil infiltration and hydrophobicity, and changes in vegetation cover, which can be consistent and quantifiable indicators in remotely sensed data. In addition, other remote sensing data obtained, for instance from Ozone Monitoring Instrument (OMI), can be used for long-term monitoring of atmospheric pollutants due to biomass burning. The OMI on-board the Aura can provide retrievals of aerosol types, such as smoke, dust, sulphur dioxide $\left(\mathrm{SO}_{2}\right)$, nitrogen dioxide $\left(\mathrm{NO}_{2}\right)$, etc.

\section{Conclusion}

This study has addressed the functionality of the new Sentinel-2 satellite to assess fire severity indices, in this case, on Madeira Island. The results may be considered as preliminary because of the limited in situ database to compare the spectral indices. These indices are often inferred using multi-temporal (pre- and post-fire) satellite remotely sensed spectra while fire severity is often estimated by visual or measured field observations of several ecological parameters. In addition, in this study we evaluate only the post-fire signal, without analysing the signal produced by the burning biomass, such as heat and smoke. However, the study made use of the beneficial spatial and temporal resolution of Sentinel-2 satellite compared with Landsat or SPOT satellites. The temporal resolution of Sentinel-2A (10 days) will increase with the launch of the twin Sentinel-2B and therefore the frequency of the combined constellation revisit will be 5 days. In the future, with the two twin Sentinel satellites in orbit, dense time series will be available.

Several indices, including the traditionally used NBR, GNDVI and NDVI indices were computed to calculate fire severity map for burnt areas and burn severity. All information related to vegetation, fire and environment can be obtained from RS 
data and can be subsequently incorporated into mapping algorithms to improve the accuracy of mapping burnt areas. The impact on ecosystem functions of burn severity, however, also depends on the pre-fire environment and vegetation types. Therefore, the mapping of burn severity provides information that gives insight into the cover patterns of post-fire vegetation and also helps to guide forest managers in conducting their restoration efforts.

Despite the few images analysed in our study, our research demonstrates that even using two images (pre- and post-fire), fire maps of burnt areas could be complied. This study opens the way to further analyse the evolution of the burnt area in the Madeira Island fires using the images of Sentinel-2. The framework exposed can likely be rapidly adopted for the assessment of many other burnt areas allowing an extremely unprecedented perspective with a unique set of accurate, robust, timely and easily accessible information, which will provide updated and reliable information on fires worldwide. Understanding the issues of fire-effects and the impact of environmental change on the ecological and biogeochemical function is of interest to a wide range of communities. In this sense, data derived from satellite observations are critically important, and remote sensing technologies are at the cross-roads in terms of sustainability management, where Governments and industry are focusing upon adapting to a changing environment. The welcome of a Sentinel-2 virtual constellation will be a major development in support of on-going activities for the environmental protection from local to global scales, which is essential in the context of addressing global challenges, such as forest fire damage assessment, planning and recovery, at regional levels.

\section{Acknowledgement}


We would like to gratefully thank the Copernicus (Sentinels Scientific Data Hub) for distributing the Sentinel-2 images used in this study. Reference data were obtained from Copernicus Emergency Management Service website (EMSR175, http://emergency.copernicus.eu/mapping/list-of-components/EMSR175). This work was financially supported by the CTM2014-58181-R and PIE201530I012 projects.

\section{References}

Barrett, K.; Kasischke, E.; McGuire, A.; Turetsky, M.; Kane, E. 2010. Modeling fire severity in black spruce stands in the Alaskan boreal forest using spectral and non-spectral geospatial data. Remote Sens. Environ., 114, 1494-1503.

Bastarrika, A.; Chuvieco, E.; Martan, M.P. 2011. Mapping burned areas from Landsat TM/ETM+ data with a two-phase algorithm: Balancing omission and commission errors. Remote Sens. Environ., 115, 1003-1012.

Chavez, P.S. 1988. An improved dark-object subtraction technique for atmospheric scattering correction of multispectral data. Remote Sens. Environ., 24(3), 459-479.

Chu, T.; Guo, X. 2014. Remote Sensing Techniques in Monitoring Post-Fire Effects and Patterns of Forest Recovery in Boreal Forest Regions: A Review. Remote Sens., 6, 470-520.

Chuvieco, E,: Martín, M.P.; Palacios, A. 2002. Assessment of different spectral indices in the red-near-infrared spectral domain for burned land discrimination. Int. J. Remote Sens., 23, 5103-5110.

Chuvieco, E. 2009. Global impacts of fire. Earth Observation of Wildland Fires in Mediterranean Ecosystems, 1-10. 
Cocke, A.E.; Fule, P.Z.; Crouse, J.E. 2005. Comparison of burn severity assessments using differenced normalized burn ratio and ground data. Int. J. Wildland Fire., 14, 189-198.

Curran, P.J.; Dungan, J.L.; Gholz, G.H.; 1990. Exploring the relationship between reflectance red edge and chlorophyll content in slash pine. Tree Physiol., 7, 3348.

Díaz-Delgado, R.; Lloret, F.; Pons, X. 2003. Influence of fire severity on plant regeneration through remote sensing imagery. Int. J. Remote Sens., 24, 17511763. doi:10.1080/ 01431160210144732

EMSR175. Forest Fire in Madeira Island. Available online: http://emergency.copernicus.eu/mapping/list-of-components/EMSR175 (accessed on 25 September 2016).

Epting, J.; Verbyla, D.; Sorbel, B. 2005. Evaluation of remotely sensed indices for assessing burn severity in interior Alaska using Landsat TM and ETM+. Remote Sens. Environ. 96, 328-339.

Escuin, S.; Navarro, R.; Fernández, P. 2008. Fire severity assessment by using NBR (Normalized Burn Ratio) and NDVI (Normalized Difference Vegetation Index) derived from LANDSAT TM/ETM images. Int. J. Remote Sens., 29,1053-1073

Eva, H.; Lambin, E.F. 1998. Burnt area mapping in Central Africa using ATSRdata. Int. J. Remote Sens., 19, 3473-3497. doi:10.1080/014311698213768

Fernández-Manso, A.; Fernández-Manso, O.; Quintano, C. 2016. SENTINEL-2A rededge spectral indices suitability for discriminating burn severity. International Journal of Applied Earth Observation and Geoinformation. 50:170-175

Flannigan, M.D.; Vonder Haar, T.H. 1986. Forest fire monitoring using NOAA satellite AVRHH. Can. J. For. Res. 16: 975-982. 
Fletcher, K. 2012. Sentinel-2: ESA's Optical High-Resolution Mission for GMES Operational Services (European Spatial Agency SP-1322/2) ISBN 978-92-9221419-7, ISSN 0379-6566.

Fraser, R.H.; Li, Z.; Cihlar, J. 2000. Hotspot and NDVI differencing synergy (HANDS): A new technique for burned area mapping over boreal forest. Remote Sens. Environ. 74, 362-376. doi:10.1016/S0034-4257(00)00078-X

Gitelson, A.A.; Kaufman, Y.J.; Merzlyak, M.N.; 1996. Use of a green channel in remote sensing of global vegetation from EOS-MODIS. Remote Sens. Environ. 58, 289298.

Holden, ZA.; Smith, AMS.; Morgan, P.; Rollins, MG.; Gessler, PE. 2005. Evaluation of novel thermally enhanced spectral indices for mapping fire perimeters and comparisons with fire atlas data. Int. J. Remote Sens., 26, 4801-4808. doi:10.1080/01431160500239008

IFRAM2, 2015. 2º Inventário Florestal Da Regiäo Autónoma Da Madeira. Relatorio Final. Direçao Regional de Florestas e Consevaçao da Natureza. Abril 2015. ISBN: 978-989-20-5641-8.

Key, C.H.; Benson, N.C. 1999. Measuring and remote sensing of burn severity: the CBI and NBR. In 'Proceedings Joint Fire Science Conference and Workshop', 15-17 June 1999, Boise, ID. (Eds LF Neuenschwander, KC Ryan) p. 282. (University of Idaho and International Association of Wildland Fire: Moscow, ID)

Kokaly, RF.; Rockwell, BW.; Haire, SL.; King ,TVV. 2007. Characterization of postfire surface cover, soils, and burn severity at the Cerro Grande Fire, New Mexico, using hyperspectral and multispectral remote sensing. Remote Sens. Environ., . $106,305-325$. 
Lentile, L.B.; Holden, Z.A.; Smith, A.M.S.; Falkowski, M.J.; Hudak, A.T.; Morgan, P.; Lewis, S.A.; Gessler, P.E.; Benson, N.C. 2006. Remote sensing techniques to assess active fire characteristics and post-fire effects. Int. J. Wildland Fire, 15, $319-345$.

López-García, MJ.; Caselles, V. 1991. Mapping burns and natural reforestation using Thematic Mapper data. Geocarto International 1, 31-37.

Malenovský, Z.; Rott, H.; Cihlar, J.; Schaepman, ME.; García-Santos, G.; Fernandes, R.; Berger, M. 2012. Sentinels for science: Potential of Sentinel-1, -2 , and -3 missions for scientific observations of ocean, cryosphere, and land. Remote Sens. Environ., 120:91-101.

Radoux, J.; Chomé, G.; Jacques, D.C.; Waldner, F.; Bellemans, N.; Matton, N.; Lamarche, C.; d'Andrimont, R.; Defourny, P. 2016. Sentinel-2's Potential for Sub-Pixel Landscape Feature Detection. Remote Sens., 8, 488.

Roy, DP.; Jin, Y.; Lewis, PE.; Justice, CO. 2005. Prototyping a global algorithm for systematic fire-affected area mapping using MODIS time series data. Remote Sens. Environ., . 97, 137-162. doi:10.1016/J.RSE.2005.04.007

Salvador, R. Valeriano, J.; Pons, X.; Díaz-Delgado, R. 2000. A semi-automatic methodology to detect fire scars in shrubs and evergreen forests with Landsat MSS time series. Int. J. Remote Sens., 21, 655-671. doi:10.1080/014311600210498

Smith, AMS.; Wooster, MJ.; Drake, NA.; Dipotso, FM.; Falkowski, MJ.; Hudak, AT. 2005. Testing the potential of multi-spectral remote sensing for retrospectively estimating fire severity in African savanna environments. Remote Sens. Environ., 97, 92-115. doi:10.1016/J.RSE.2005.04.014 
Stroppiana, D.; Pinnock, S.; Pereira, JMC.; Grégoire, JM. 2002. Radiometric analysis of SPOT-VEGETATION images for burnt area detection in Northern Australia. Remote Sens. Environ., 82, 21-37. doi:10.1016/S0034-4257(02)00021-4.

Toming, K.; Kutser, T.; Laas, A.; Sepp, M.; Paavel, B.; Nõges, T. 2016. First Experiences in Mapping Lake Water Quality Parameters with Sentinel-2 MSI Imagery. Remote Sens., 8, 640.

T.V.D. GmbH, 2015. Sentinel-2 MSI-Level-2A Prototype Processor Installation and User Manual. Available online: http://step.esa.int/main/third-party-plugins2/sen2cor/ (accessed on 6 October 2016).

van Wagtendonk, JW; Root, RR.; Key, CH. 2004. Comparison of AVIRIS and Landsat ETM+ detection capabilities for burn severity. Remote Sens. Environ., 92:397408 


\section{Figure Captions}

Fig. 1. a) Location of the study area (square box indicates the location of the Madeira Archipelago). b) Madeira Archipelago (Madeira, Porto Santo and Desertas Islands). c) Madeira Island map. d) Pre-fire RGB Sentinel-2A MSI image corresponding to Madeira Island.

Fig. 2. a) Post-fire RGB (4-3-2) Sentinel-2A MSI image corresponding to Madeira Island. Distribution of areas depending on the fire grading obtained from Copernicus Emergency Management Service website (CD: completely destroyed area; HD: highly damaged area; MD: moderately damaged area; and PD: possibly damaged area) for b) Calheta fire and c) Funchal fire.

Fig. 3. Spectral index maps for the Normalized Difference Vegetation Index (NDVI) of the Madeira Island for: a) pre-fire b) post-fire and c) NDVI difference (dNDVI).

Fig. 4. Spectral index maps for the Green Normalized Difference Vegetation Index (GNDVI) of the Madeira Island for: a) pre-fire b) post-fire and c) GNDVI difference (dGNDVI).

Fig. 5. Spectral index maps for the Normalized Burn Ratio (NBR) of the Madeira Island for: a) pre-fire b) post-fire and c) NBR difference (dNBR).

Fig. 6. Box-plot of spectral index (NDVI, GNDVI and NBR) for each area depending on the fire grading (CD, HD and MD) for Calheta fire.

Fig. 7. Spectral index maps for the Normalized Difference Vegetation Index red-edge bands (NDVIre1n, NDVIre2n and NDVIre3n) of the Madeira Island for pre-fire, postfire and index difference.

Fig. 8. Box-plot of spectral index (NDVIre1n, NDVIre2n and NDVIre3n) for each area depending on the fire grading (CD, HD and MD) for Calheta fire. 

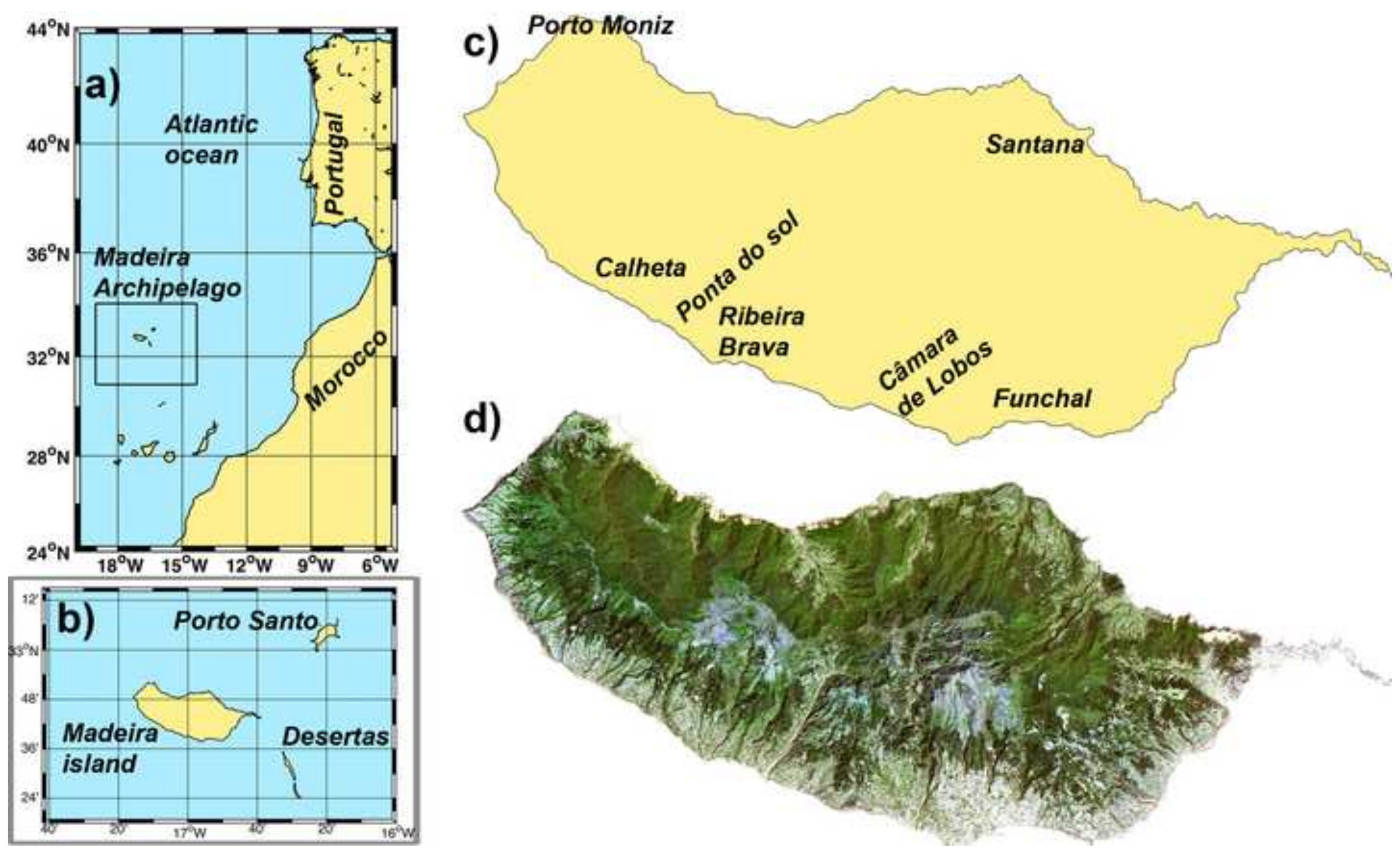
Click here to download high resolution image
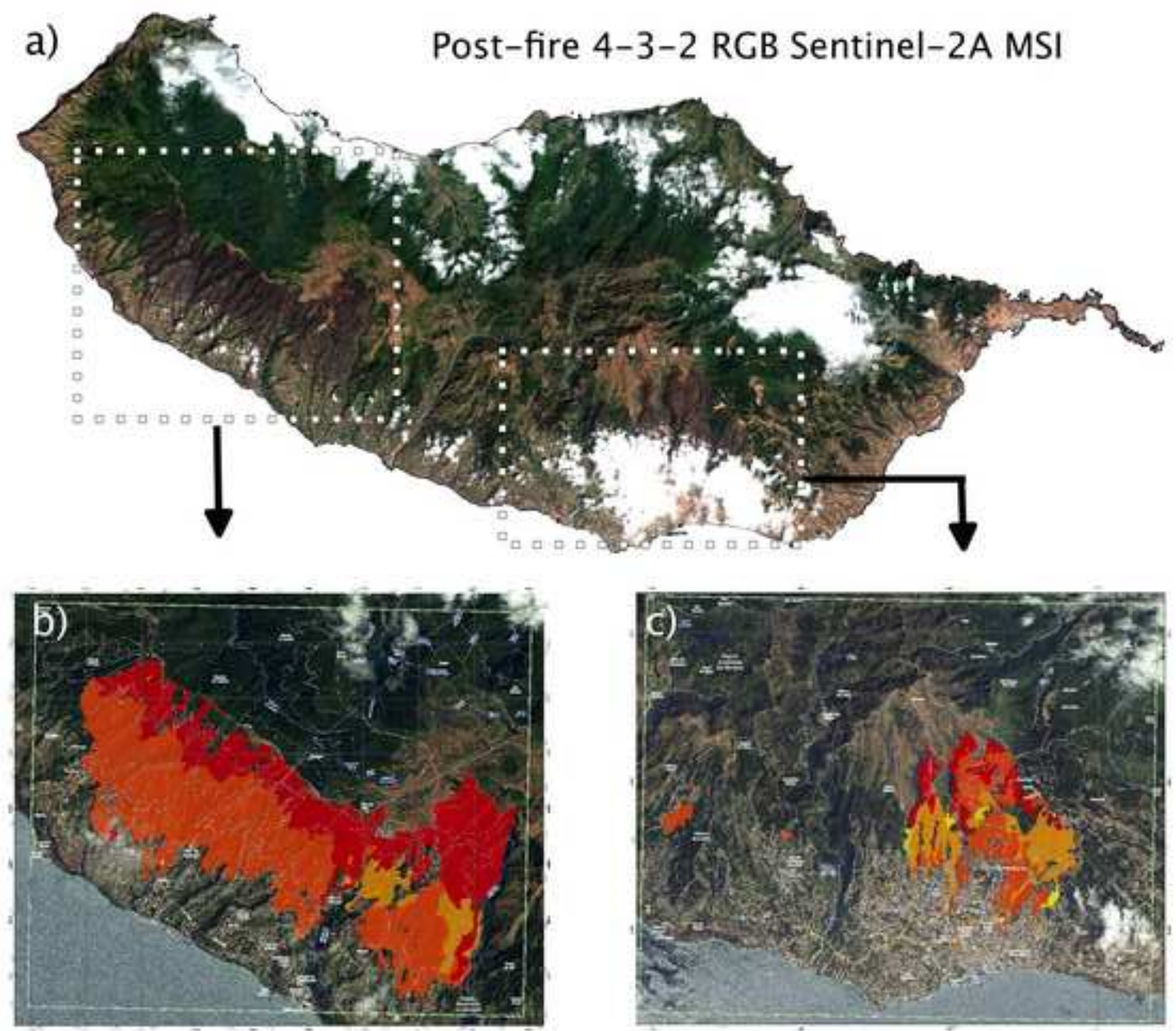

Fire Grading:

$\square$ destroyed

Highly damaged 

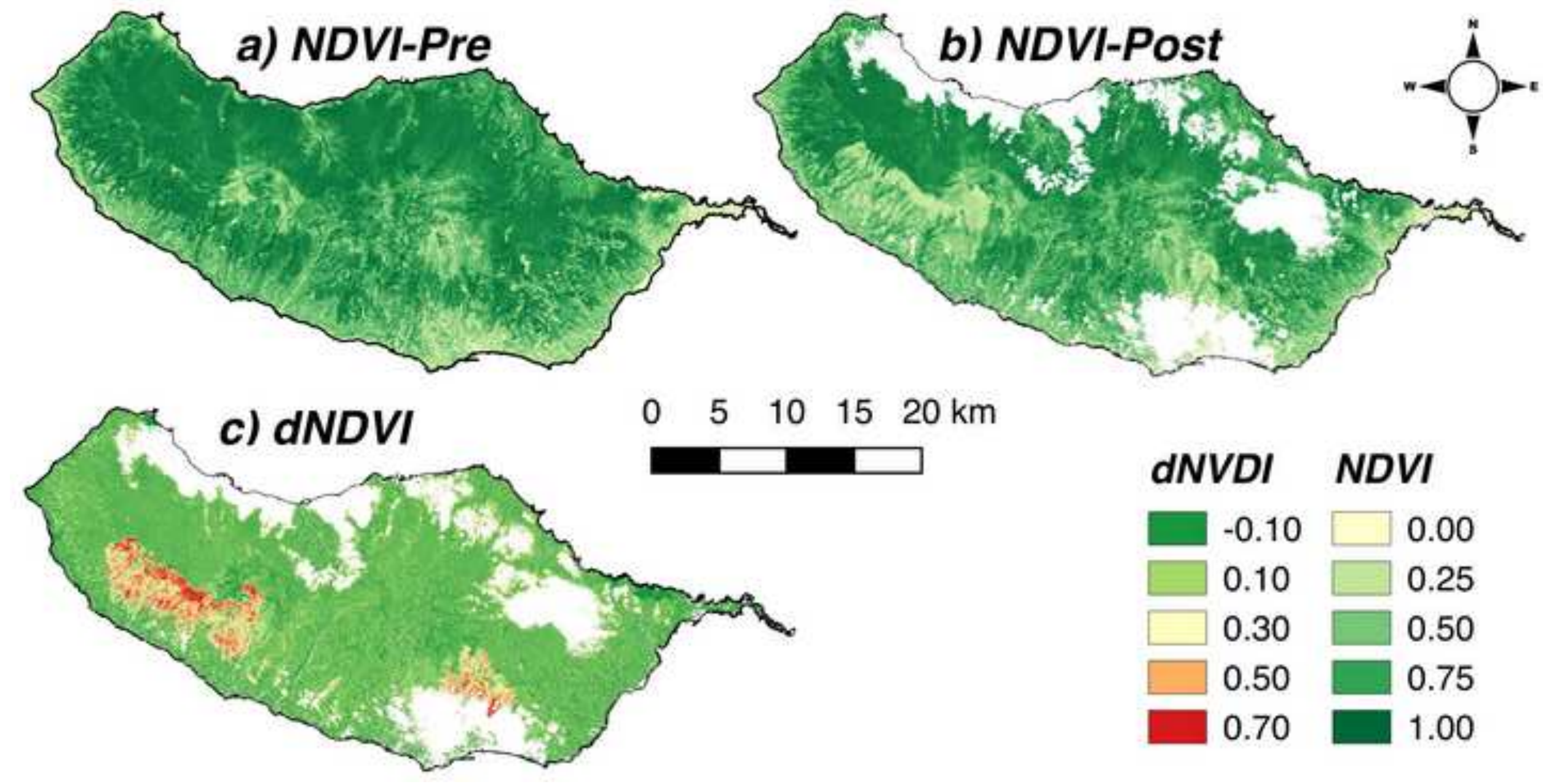

dNVDI NDVI

\begin{tabular}{|c|c|}
\hline & \\
\hline-0.10 & 0.00 \\
\hline 0.10 & 0.25 \\
\hline 0.30 & 0.50 \\
\hline 0.50 & 0.75 \\
\hline 0.70 & 1.00 \\
\hline
\end{tabular}

$1520 \mathrm{~km}$

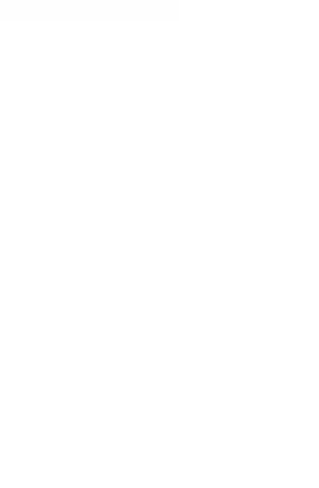



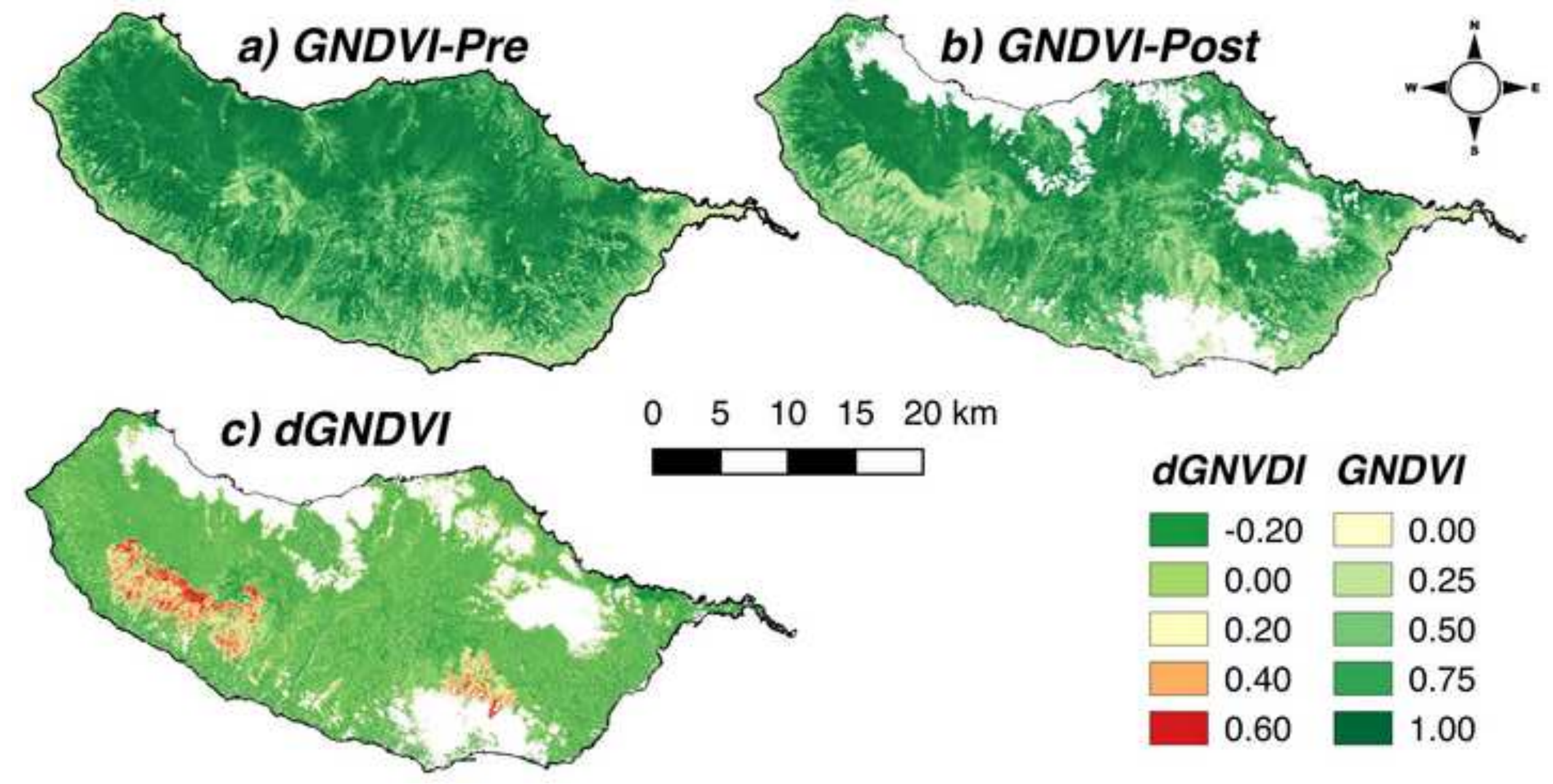

dGNVDI GNDVI

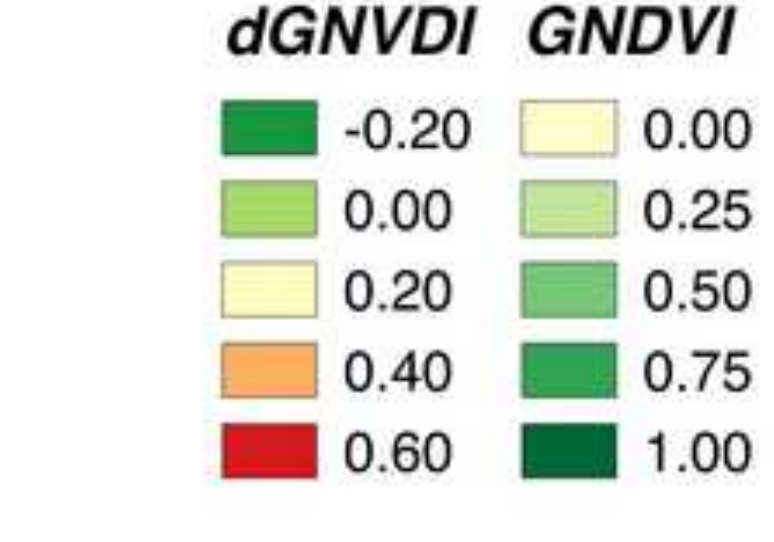



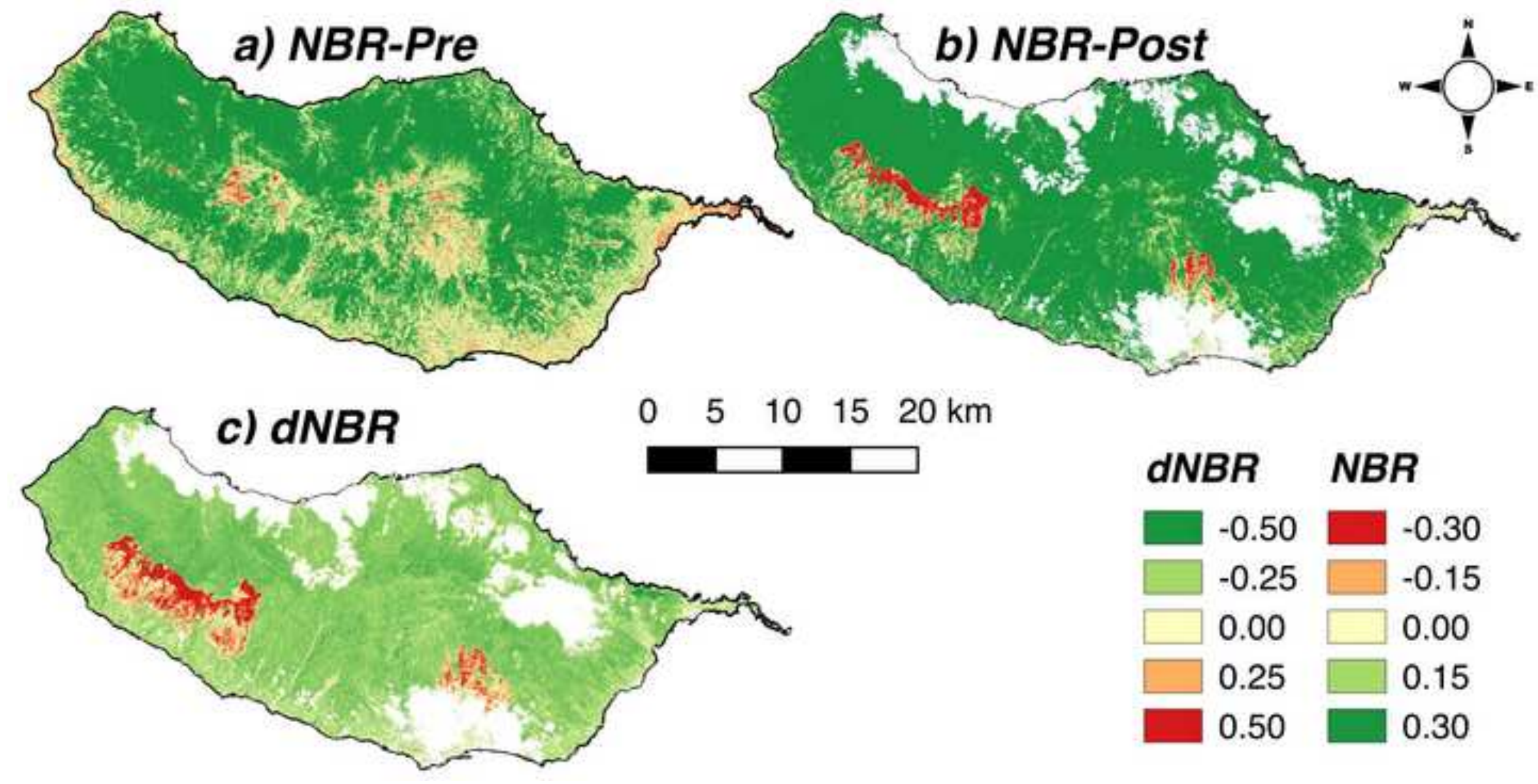

dNBR NBR

\begin{tabular}{|c|c|}
\hline-0.50 & -0.30 \\
\hline-0.25 & -0.15 \\
\hline 0.00 & 0.00 \\
\hline 0.25 & 0.15 \\
\hline 0.50 & 0.30 \\
\hline
\end{tabular}

$1520 \mathrm{~km}$

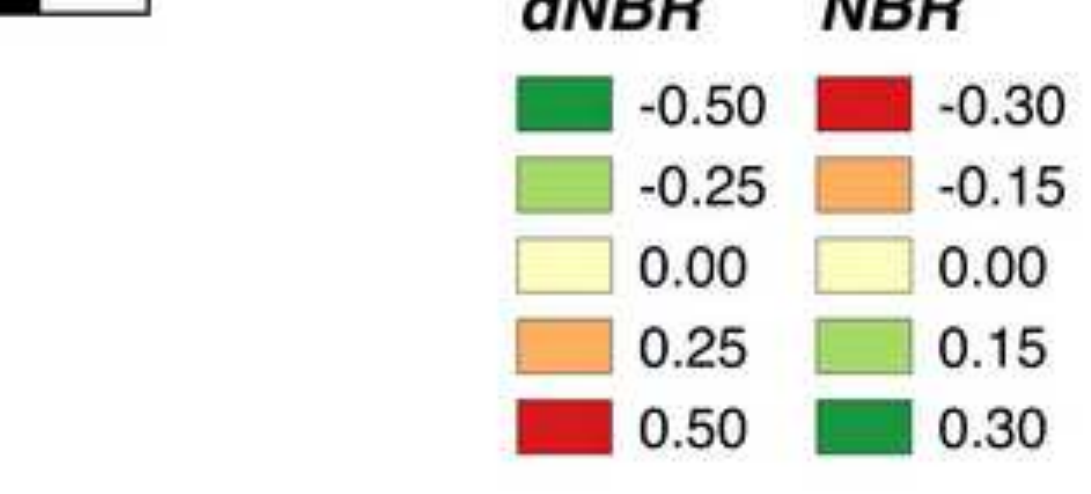



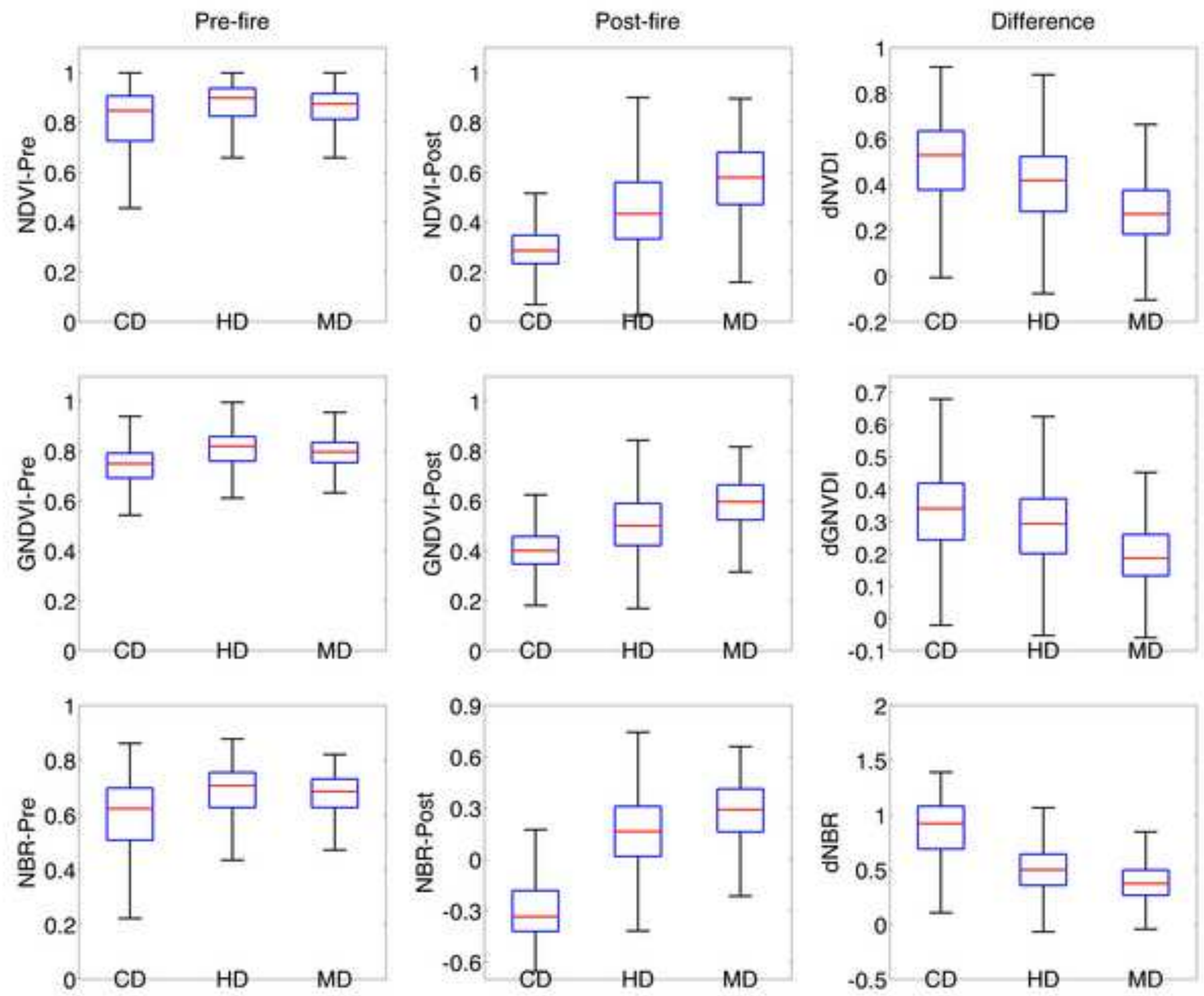
Click here to download high resolution image
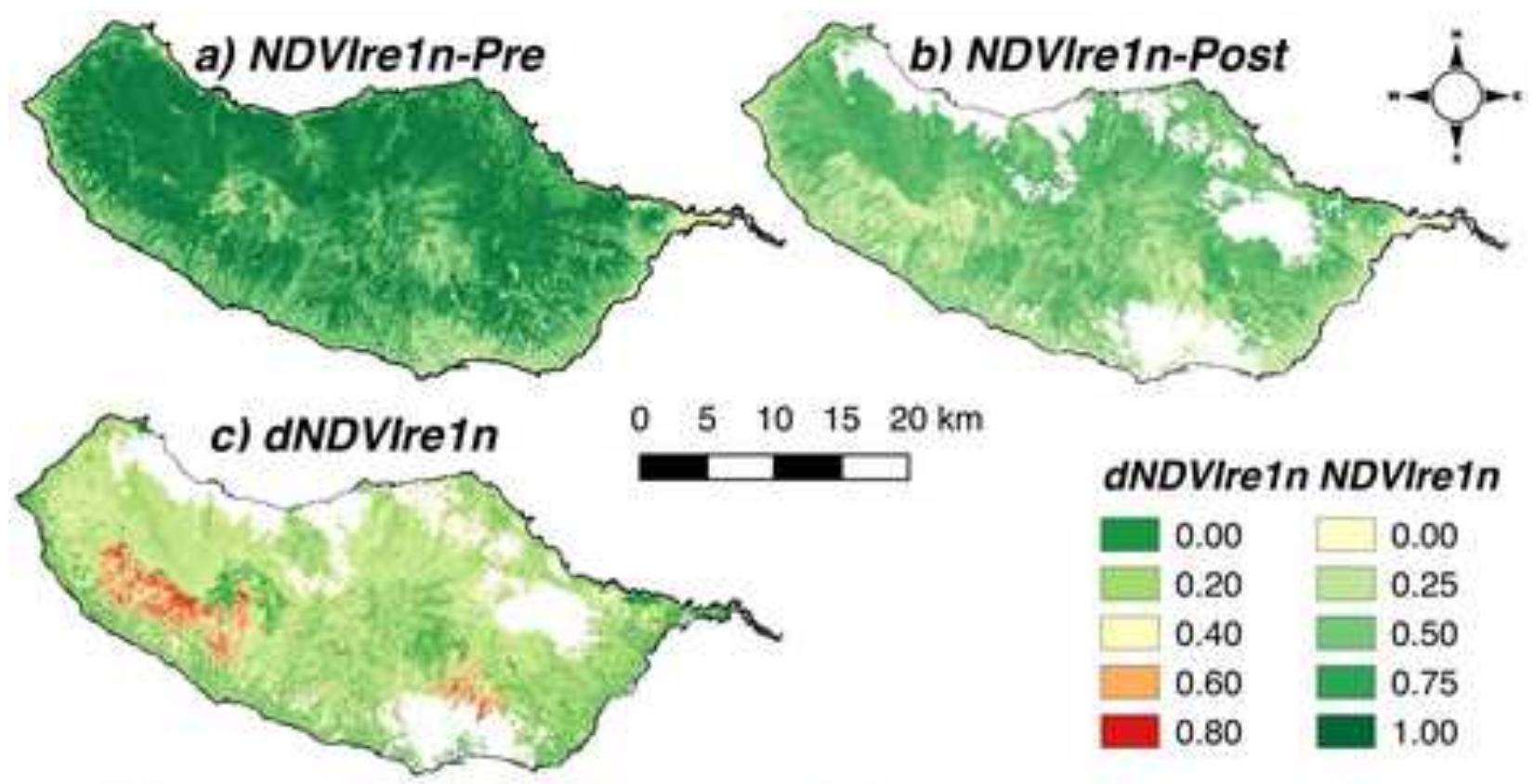

dNDVIre1n NDVIre1n
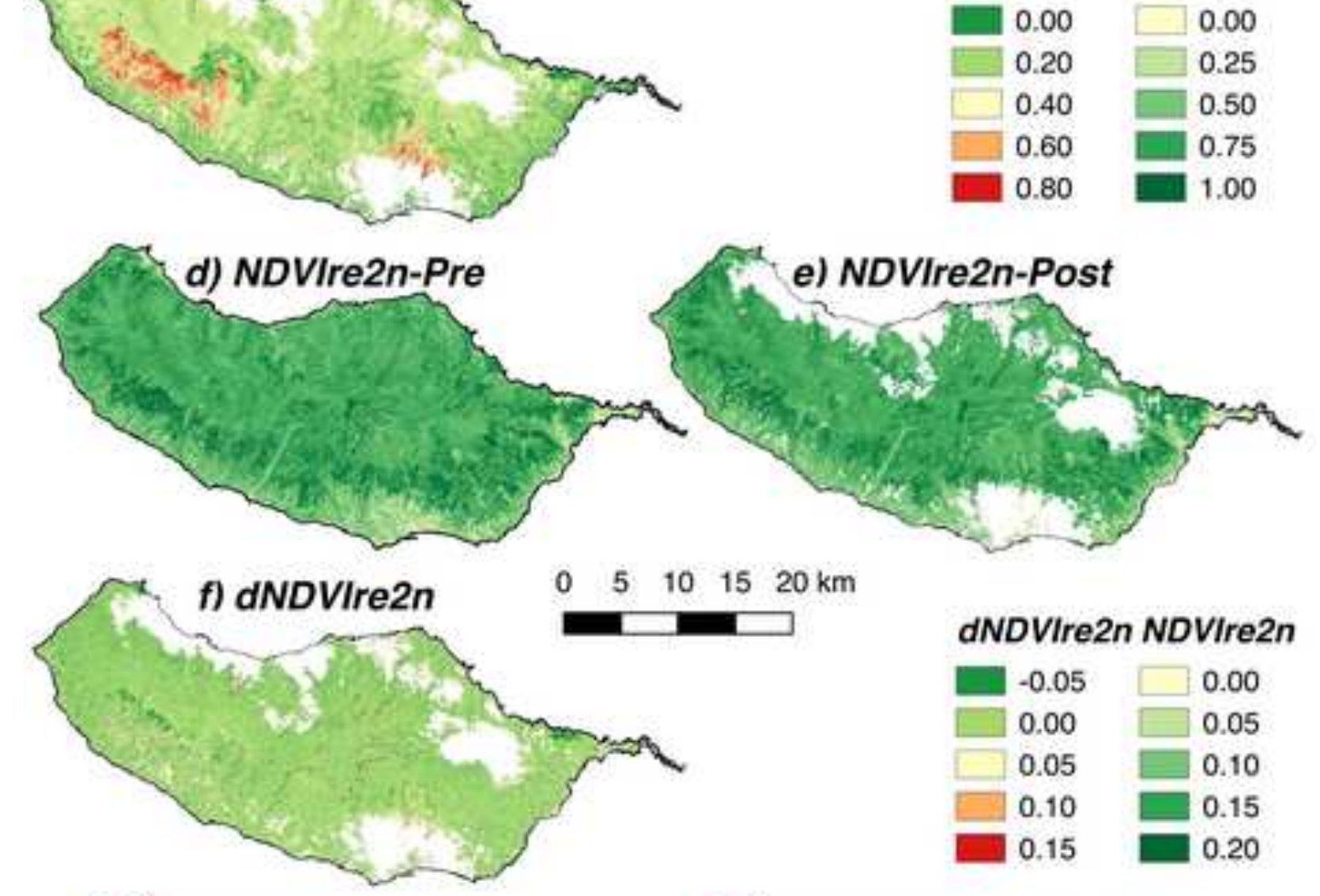

dNDVIre2n NDVIre2n
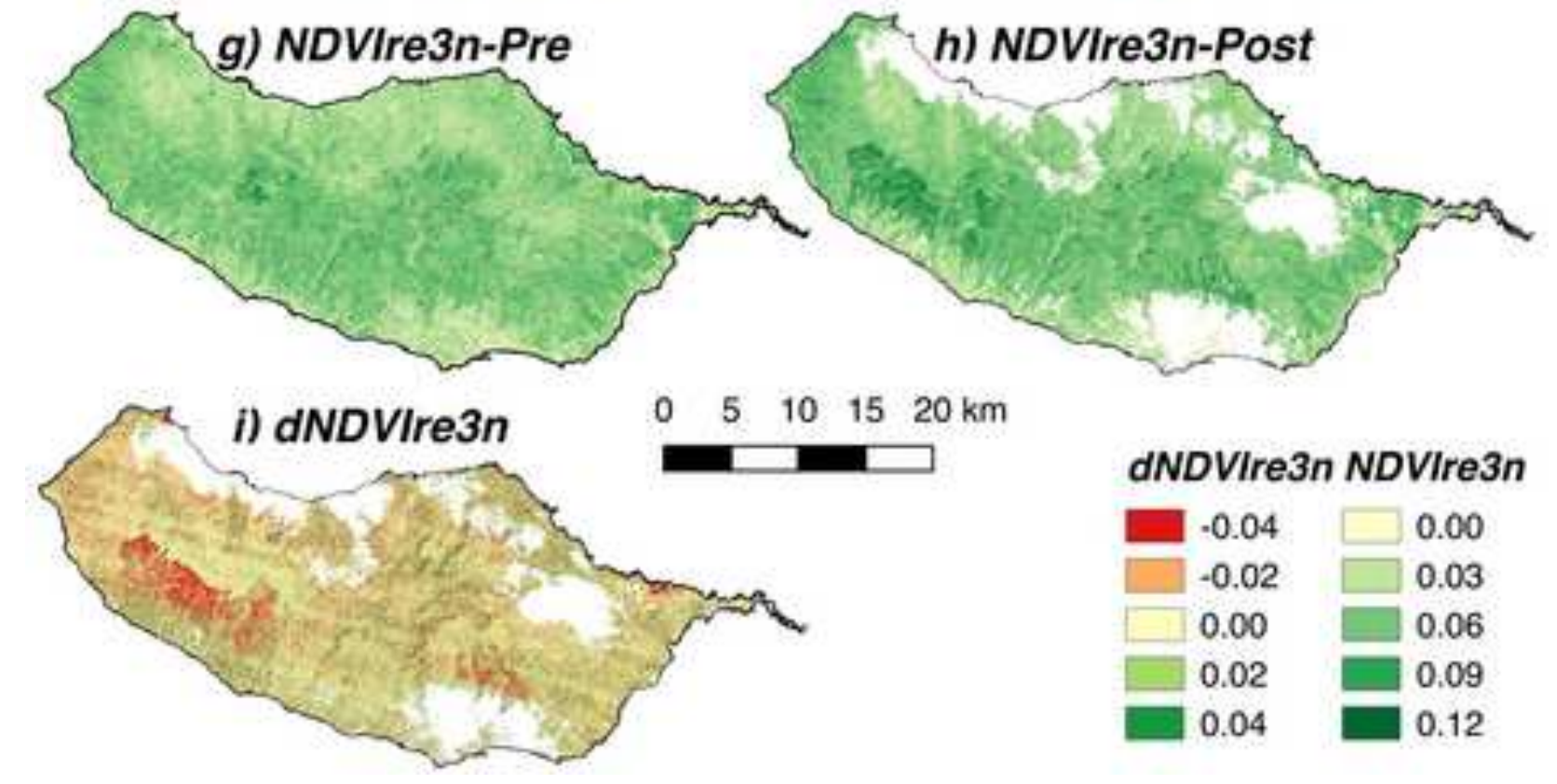

dNDVIre3n NDVIre3n
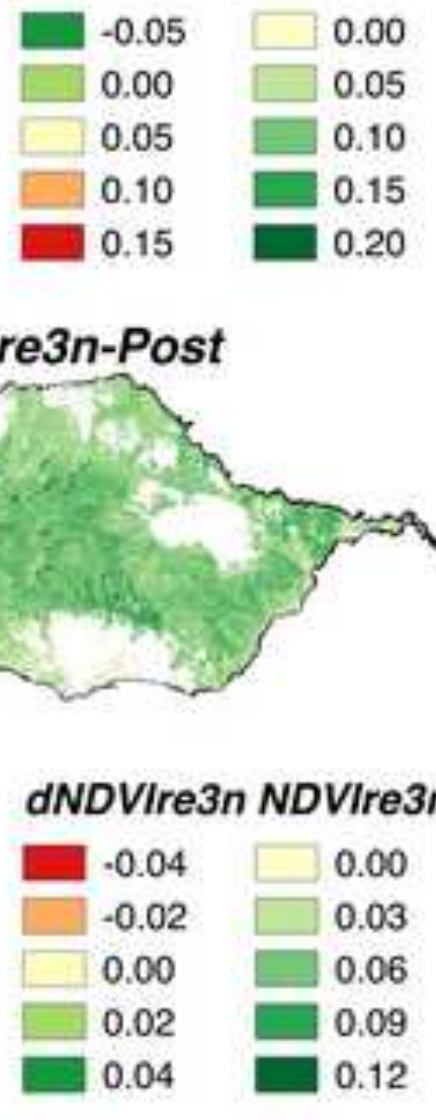

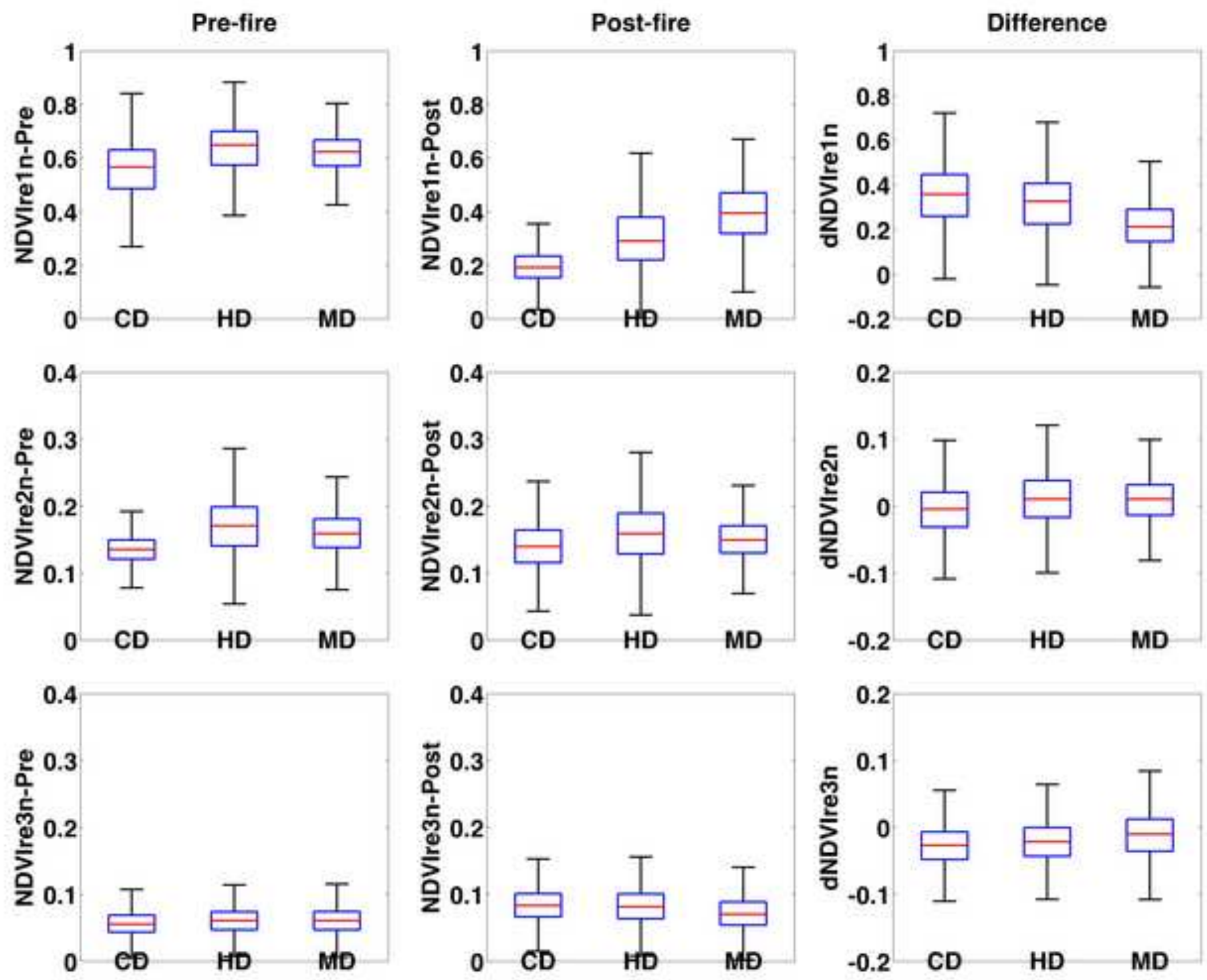
Table 1. Sentinel-2A MSI band settings.

\begin{tabular}{|c|c|c|c|c|}
\hline Acronym & Band & $\begin{array}{c}\text { Central Wave- } \\
\text { length }(\mathbf{n m})\end{array}$ & $\begin{array}{c}\text { Spectral Width } \\
(\Delta \mathbf{\lambda} \mathbf{~} \mathbf{m})\end{array}$ & $\begin{array}{c}\text { Spatial } \\
\text { resolution }(\mathbf{m})\end{array}$ \\
\hline B1 & Violet & 443 & 20 & 60 \\
\hline B2 & Blue & 490 & 65 & 10 \\
\hline B3 & Green & 560 & 35 & 10 \\
\hline B4 & Red & 665 & 30 & 10 \\
\hline B5 & Red-edge 1 & 705 & 15 & 20 \\
\hline B6 & Red-edge 2 & 740 & 15 & 20 \\
\hline B7 & Red-edge 3 & 783 & 20 & 20 \\
\hline B8 & NIR & 842 & 115 & 10 \\
\hline B8a & NIR narrow & 865 & 20 & 20 \\
\hline B9 & NIR & 945 & 20 & 60 \\
\hline B10 & NIR & 1380 & 30 & 60 \\
\hline B11 & SWIR1 & 1610 & 90 & 20 \\
\hline B12 & SWIR2 & 2190 & 180 & 20 \\
\hline
\end{tabular}


Table 2. Dates of the fires and pre-/post-fire images employed in this study.

\begin{tabular}{|c|c|l|}
\hline & $\begin{array}{c}\text { Acquisition time } \\
\text { (GMT) }\end{array}$ & \multicolumn{1}{|c|}{ Filename of the image } \\
\hline \multirow{2}{*}{ Pre-fire } & $2016 / 08 / 07$ & S2A_OPER_PRD_MSIL1C_PDMC_20160808T0012 \\
& $12: 02: 22$ & 40_R023_V20160807T120222_20160807T120222 \\
\hline \multirow{2}{*}{ Post-fire } & $2016 / 08 / 17$ & S2A_OPER_PRD_MSIL1C_PDMC_20160817T2347 \\
& $12: 02: 22$ & 56_R023_V20160817T120222_20160817T120221 \\
\hline
\end{tabular}


Table 3. Spectral indices used in this study.

\begin{tabular}{|c|c|c|c|}
\hline Acronym & Spectral index & Formula & Equation \\
\hline \multirow[t]{2}{*}{ NDVI } & \multirow{2}{*}{$\begin{array}{l}\text { Normalized Difference } \\
\text { Vegetation Index }\end{array}$} & $(N I R-r e d)$ & $(B 8 a-B 4)$ \\
\hline & & $\overline{(N I R+r e d)}$ & $\overline{(B 8 a+B 4)}$ \\
\hline \multirow[t]{2}{*}{ GNDVI } & \multirow{2}{*}{$\begin{array}{c}\text { Green Normalized } \\
\text { Difference Vegetation } \\
\text { Index }\end{array}$} & $(N I R-$ green $)$ & $(B 8 a-B 3)$ \\
\hline & & $(N I R+$ green $)$ & $(B 8 a+B 3)$ \\
\hline \multirow[t]{2}{*}{ NBR } & \multirow[t]{2}{*}{ Normalized Burn Ratio } & $(N I R-S W I R 2)$ & $(B 8 a-B 12)$ \\
\hline & & $\overline{(N I R+S W I R 2)}$ & $\overline{(B 8 a+B 12)}$ \\
\hline \multirow[t]{2}{*}{ NDVIre1n } & \multirow{2}{*}{$\begin{array}{c}\text { Normalized Difference } \\
\text { Vegetation Index red-edge } \\
1 \text { narrow }\end{array}$} & $(N I R-$ red edge 1$)$ & $(B 8 a-B 5)$ \\
\hline & & $(N I R+$ red edge 1$)$ & $(B 8 a+B 5)$ \\
\hline \multirow[t]{2}{*}{ NDVIre2n } & \multirow{2}{*}{$\begin{array}{c}\text { Normalized Difference } \\
\text { Vegetation Index red-edge } \\
2 \text { narrow }\end{array}$} & $(N I R-$ red edge 2$)$ & $(B 8 a-B 6)$ \\
\hline & & $\overline{(N I R+\text { red edge } 2)}$ & $\overline{(B 8 a+B 6)}$ \\
\hline \multirow[t]{2}{*}{ NDVIre3n } & \multirow{2}{*}{$\begin{array}{l}\text { Normalized Difference } \\
\text { Vegetation Index red-edge } \\
3 \text { narrow }\end{array}$} & $(N I R-$ red edge 3$)$ & $(B 8 a-B 7)$ \\
\hline & & $\overline{(N I R+\text { red edge } 3)}$ & $\overline{(B 8 a+B 7)}$ \\
\hline dNDVI & NDVI difference & \multicolumn{2}{|c|}{$\mathrm{NDVI}_{\text {pre }}-\mathrm{NDVI}_{\text {post }}$} \\
\hline dGNDVI & GNDVI difference & \multicolumn{2}{|c|}{ GNDVI $_{\text {pre }}-G_{N D V I}$ post } \\
\hline dNBR & NBR difference & \multicolumn{2}{|c|}{$\mathrm{NBR}_{\text {pre }}-\mathrm{NBR}_{\text {post }}$} \\
\hline dNDVIre1n & NDVIre1n difference & \multicolumn{2}{|c|}{ NDVIre $1 n_{\text {pre }}-\mathrm{NDVIre} 1 \mathrm{n}_{\text {post }}$} \\
\hline dNDVIre2n & NDVIre2n difference & \multicolumn{2}{|c|}{ NDVIre $2 n_{\text {pre }}-N D V I r e 2 n_{\text {post }}$} \\
\hline dNDVIre3n & NDVIre3n difference & \multicolumn{2}{|c|}{ NDVIre $3 n_{\text {pre }}-N D V I r e 3 n_{\text {post }}$} \\
\hline
\end{tabular}


Table 4. Statistical values (median, percentile 25 and percentile 75 ) of the spectral indices for each area (fire grading) in Calheta fire.

\begin{tabular}{|c|c|c|c|c|}
\hline $\begin{array}{c}\text { Spectral } \\
\text { index }\end{array}$ & $\begin{array}{c}\text { Fire } \\
\text { grading }\end{array}$ & $\begin{array}{c}\text { Pre-fire } \\
\text { Median [P25 : P75] }\end{array}$ & $\begin{array}{c}\text { Post-fire } \\
\text { Median [P25-P75] }\end{array}$ & $\begin{array}{c}\text { difference } \\
\text { Median [P25-P75] }\end{array}$ \\
\hline \multirow{3}{*}{ NDVI } & $\mathrm{CD}$ & $0.8469[0.7260: 0.9064]$ & $0.2845[0.2329: 0.3459]$ & $0.5288[0.3778: 0.6344]$ \\
\cline { 2 - 5 } & $\mathrm{HD}$ & $0.8980[0.8250: 0.9366$ & $0.4325[0.3323: 0.5594]$ & $0.4185[0.2829: 0.5222]$ \\
\cline { 2 - 5 } & $\mathrm{MD}$ & $0.8980[0.8126: 0.9158$ & $0.4325[0.4706: 0.6794]$ & $0.4185[0.1824: 0.3753]$ \\
\hline & $\mathrm{CD}$ & $0.7494[0.6921: 0.7918$ & $0.4004[0.3470: 0.4581]$ & $0.3396[0.2425: 0.4186]$ \\
\cline { 2 - 5 } GNDVI & $\mathrm{HD}$ & $0.8196[0.7599: 0.8585$ & $0.5006[0.4217: 0.5906]$ & $0.2933[0.2008: 0.3706]$ \\
\cline { 2 - 5 } & $\mathrm{MD}$ & $0.8196[0.7539: 0.8350$ & $0.5006[0.5242: 0.6642]$ & $0.2933[0.1317: 0.2600]$ \\
\hline \multirow{3}{*}{ NBR } & $\mathrm{CD}$ & $0.6228[0.5078: 0.6982$ & $-0.3344[-0.4206:-0.1828]$ & $0.9208[0.6892: 1.0785]$ \\
\cline { 2 - 5 } & $\mathrm{HD}$ & $0.7070[0.6267: 0.7545$ & $0.1637[0.0177: 0.3088]$ & $0.4989[0.3574: 0.6402]$ \\
\cline { 2 - 5 } & $\mathrm{MD}$ & $0.7070[0.6268: 0.7305$ & $0.1637[0.1609: 0.4121]$ & $0.4989[0.2665: 0.4979]$ \\
\hline \multirow{3}{*}{ NDVIre1n } & $\mathrm{CD}$ & $0.5666[0.4864: 0.6312$ & $0.1914[0.1536: 0.2342]$ & $0.3585[0.2593: 0.4468]$ \\
\cline { 2 - 5 } & $\mathrm{HD}$ & $0.6497[0.5748: 0.7006$ & $0.2906[0.2200: 0.3794]$ & $0.3264[0.2252: 0.4073]$ \\
\cline { 2 - 5 } & $\mathrm{MD}$ & $0.6497[0.5710: 0.6678$ & $0.2906[0.3191: 0.4704]$ & $0.3264[0.1468: 0.2904]$ \\
\hline & $\mathrm{CD}$ & $0.1355[0.1210: 0.1496$ & $0.1399[0.1159: 0.1643]$ & $-0.0043[-0.0309: 0.0209]$ \\
\cline { 2 - 5 } & $\mathrm{HD}$ & $0.1709[0.1410: 0.1989$ & $0.1591[0.1287: 0.1894]$ & $0.0107[-0.0167: 0.0384]$ \\
\cline { 2 - 5 } & $\mathrm{MD}$ & $0.1709[0.1385: 0.1809$ & $0.1591[0.1303: 0.1709]$ & $0.0107[-0.0132: 0.0321]$ \\
\hline \multirow{3}{*}{ NDVIre2n } & $\mathrm{CD}$ & $0.0557[0.0434: 0.0691$ & $0.0836[0.0667: 0.1012]$ & $-0.0268[-0.0480:-0.0064]$ \\
\cline { 2 - 5 } & $\mathrm{HD}$ & $0.0607[0.0472: 0.0739$ & $0.0817[0.0635: 0.1006]$ & $-0.0214[-0.0430:-0.0000]$ \\
\cline { 2 - 5 } & $\mathrm{MD}$ & $0.0607[0.0469: 0.0744$ & $0.0817[0.0541: 0.0887]$ & $-0.0214[-0.0355: 0.0127]$ \\
\hline
\end{tabular}

